patulous. In either case a diagnosis can be made only by a curettage and examination of the curettings.

If one examination is negative and the curettage does not give relief, the uterus should be explored a second, third or even a fourth time, for the disease, as we have seen, may be detected only after repeated examinations of the endometrium.

Better results in the treatment of cancer of the uterus can be obtained only by earlier recognition. This can be accomplished, in the first place, by dissemination of information concerning it among the laity; and, in the second, by making the thorough examination of the patient, including the use of the microscope, a routine procedure in all cases which present suspicious symptoms.

\section{ANTERIOR METATARSALGIA: ITS CAUSES AND ITS RELIEF.}

BY NATHaniel ALLISON, M.D., st. Lovis, mo.,

Clinical Lecturer on Orthopedic Surgery, Washington University, St Louis; Member of the American Orthopedic Association.

THE pain and disability of the anterior part of the foot which is called anterior metatarsalgia has causes which may be separated into those predisposing and those that actually produce the condition. The latter are chiefly anatomical. Those that have a predisposing influence are, for the most part, a lack of muscular use of the anterior foot and the tight bandaging and splinting of the anterior foot in a shoe; secondary to these is the influence of increase in weight which comes with adult life and the pursuit of sedentary occupations. A few moments' thought upon the subject will convince any one that it is not at all to be wondered at that so many persons suffer pain and disability in this portion of their feet, an observation which is especially easy in considering the impossible footwear used by the majority of women. For many generations it has been the custom among shoe-wearing races to tightly splint and bandage the foot from early childhood on in a shoe, thus converting the foot into a veritable hoof. Along with this maltreatment of the human foot there has developed a vanity and mental weakness which makes most every one desire to have a small, narrow and inefficient foot. This development is exceedingly interesting when one considers its relationship to art. The mental aberration which causes us to recognize as a point of beauty a foot that is small to the extent of being absolutely out of proportion, that is, narrow and deformed anteriorly is perhaps too deep a question in the history of morals and philosophy to discuss in an article of this nature, being a question more for the artist and sculptor than for the surgeon. It remains, however, for us to treat these inefficiencies which are so persistently and foolishly developed.

As a predisposing cause, the shoe occupies a place in the first rank. It is recognized clinically that women are affected with these troubles more than twice as frequently as men; also that the majority of those who suffer from anterior metatarsalgia are patients representing the so-called better class of society; which, reduced to lowest terms, mean that, as a rule, men wear more sensible shoes than women and that those who make their livelihood by brawn instead of brain find it necessary to wear a shoe which does not cramp and pinch their feet. The pointed, narrow shoe which does not allow the anterior part of the foot to be used as a muscular apparatus, particularly if this shoe has an elevated heel, is the most potent factor in the development of the weak, atrophied, callosed and deformed anterior foot. Furthermore, it may be remarked that these predisposing causes fall into the form of a vicious circle; that is to say, the more the individual does not use the foot, the more is the foot unfit to be used; and the more the foot is unfit for use, the more will the individual be inclined not to use it.

The anatomical causes are those that actually cause the pain in these cases. They have been more or less generally understood since Morton, ${ }^{1}$ in 1876, wrote the communication which gives to him the honor of having this trouble called by his name. He described the causation of pain as due to the fact that the fifth metatarsophalangeal joint is much posterior to the fourth, thus bringing the base of the first phalanx of the little toe opposite the head and neck of the fourth metatarsal. Accidental compression of the branches of the external plantar nerve is thus produced, due to the greater mobility of the outer metatarsal bones.

Goldthwait, ${ }^{2}$ in 1894 , wrote an admirable paper which took up carefully the anatomy and the mechanics of this part of the foot, especially where the anterior arch of the foot was causing symptoms. He states: "The location of the pain in the interspace between the fourth and fifth metatarsal bones, that which is described by Morton as being the commonest, is certainly unusual, and the cases are strikingly few when compared with those in which the pain is referred to the middle of the foot. The callus, which may vary considerably in size, is formed directly under the heads of the second and third metatarsal bones as the result of undue pressure at this point and at times is so painful as to make locomotion difficult." Goldthwait also proved his observation by tracings of the soles of the feet which showed a loss of what he calls the " re-entering angle " under the second and third metatarsal heads in cases which present marked symptoms.

R. Jones ${ }^{3}$ has attributed the pain to an abnormal relationship of the anterior ends of the metatarsal bones, which allows them to pinch the external plantar nerve between the ends or allows them to press on the digital nerves or which produces abnormal strain on the ligaments connecting the heads of the bones.

Certain it is that the pain is due to crowding downwards of the metatarsal heads as the foot slips forward in the narrow shoe. The weight of the body in standing and walking has been shown to be borne normally by the first and fourth metatarsal bones. The illustration (Fig. 1), borrowed from Piersol's new anatomy, shows the normal relationship of the anterior ends of the 
metatarsal bones. It is here shown that weakening and collapse of the anterior transverse arch of the foot allows the foot to become broadened laterally; also that it allows the heads of the second and third metatarsal bones to descend under weight and thus produce the characteristic callus described by Goldthwait and later by Hardaway and myself.

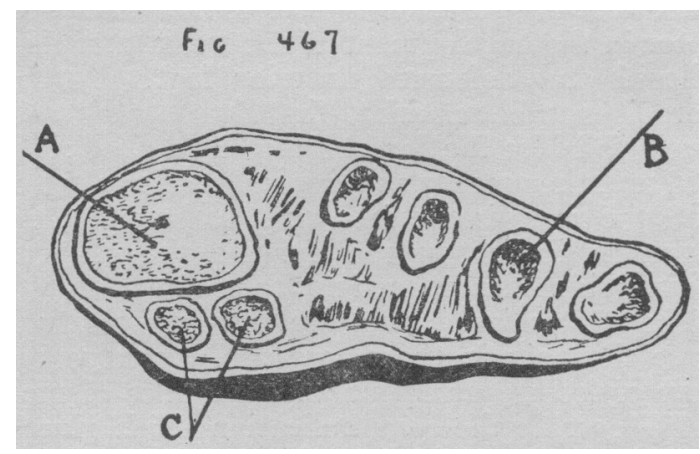

FIG. 1. Section of right foot through heads of metatarsal bones, showing support by first and fourth. ("Human tarsal. $B$. Fourth metarsal. C. Sesamoid bones.

The characteristic pain in these cases is also produced by the same descent of the anterior ends of the second and third metatarsals, which thus press upon the plantar digital nerves, which nerves are not between the bones but are superficial to them, consequently are not pinched between the bones but are pressed upon the

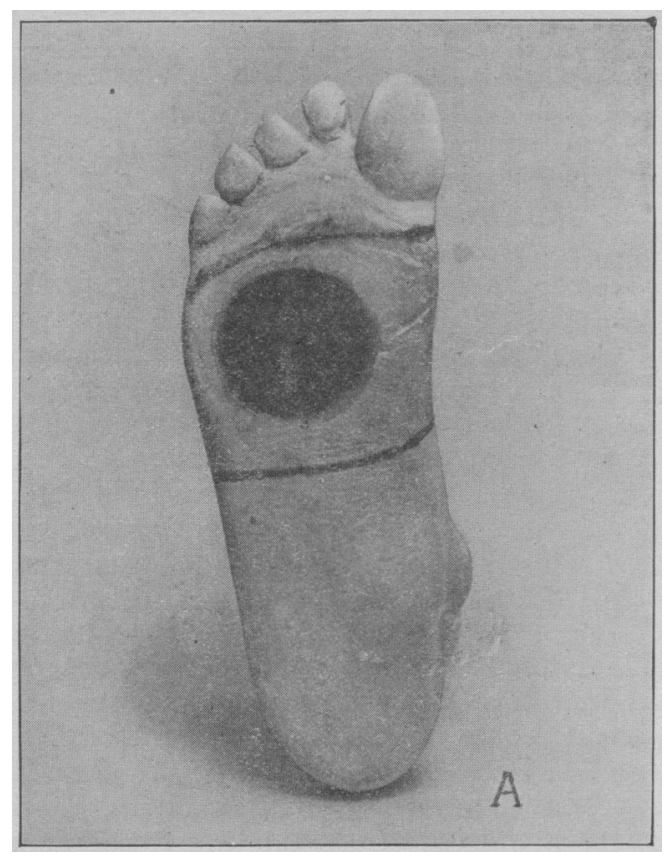

FIG. 2 A. Depression cut in"sole of plaster cast for the pad, and markings for limits of leather bandage.

structure beneath the bones as weight is borne. This anatomical observation explains the great variation in the description of the pain. It is not always acutely paroxysmal but ranges from an acute, knife-like pain to a dull, aching and burning in the front of the foot.
So much for the actual causes, which are well understood and are only reviewed here in order that the treatment which I have to recommend

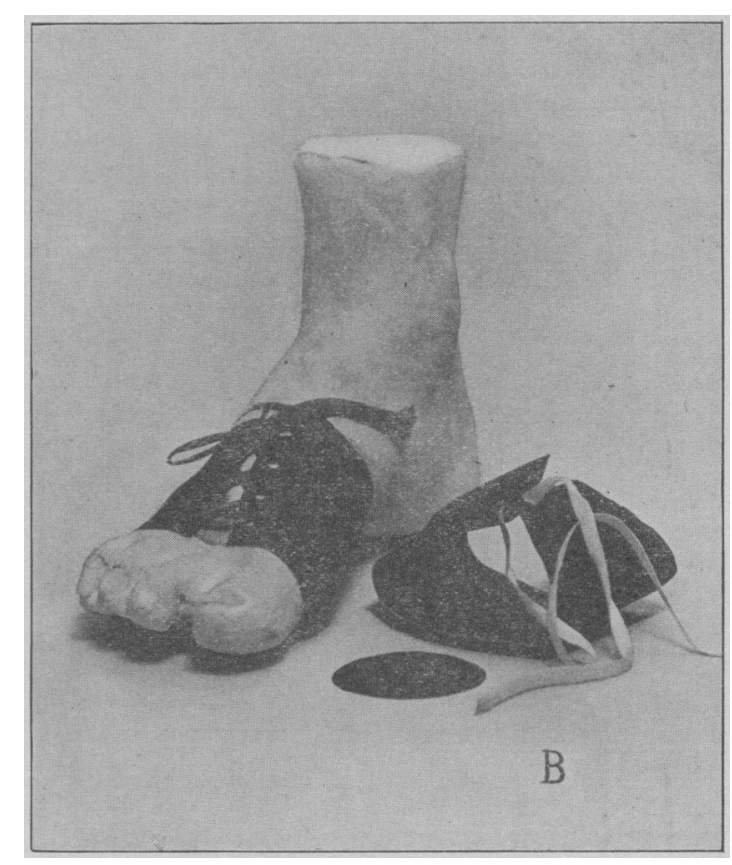

Fig. 2 B. A leather bandage in place on the foot; also a pad which is thus held under the anterior arch.

may be clearly understood. Before passing on to this, however, I would like to state that this condition is often associated with a high degree

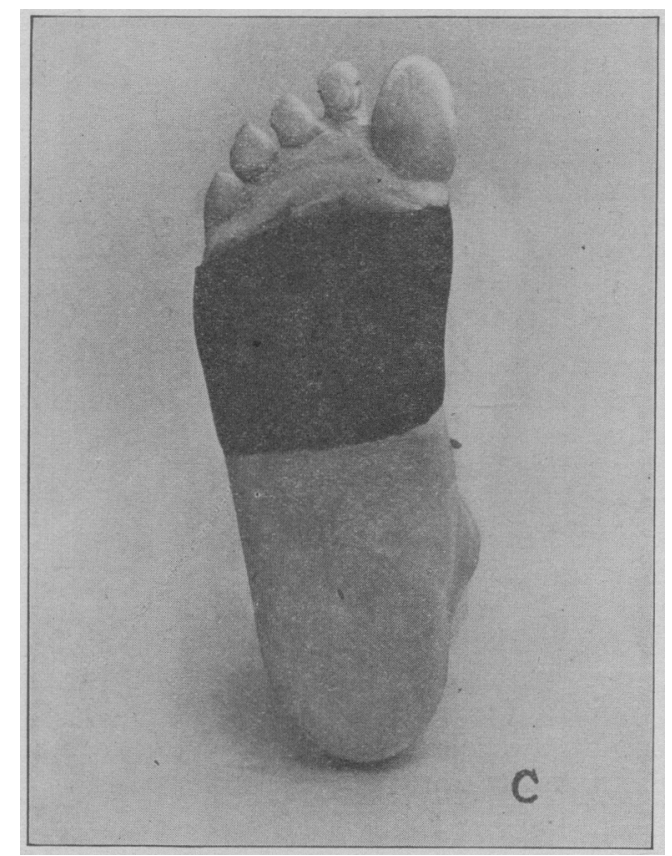

FIG. 2 C. Sole of foot with leather bandage in place.

of neurasthenia, so much so that Dr. Sidney I. Schwab and $I$ are engaged in making a special study of the overlap which exists between ortho- 
pedics and neurology on this point. The relationship of orthopedics to dermatology in this and similar conditions has been pointed out by Dr. W. A. Hardaway ${ }^{4}$ and myself in an article which called attention to the close association existing between warty growths, callosities and hyperidrosis and malpositions of the feet.

The treatment which I have to recommend for these cases is of the simplest possible nature. Briefly it consists of support and developmental exercises. Support to the sunken or sinking anterior arch of the foot is nothing new, its value being well established. The question of how support should be applied is, however, a question which entails many difficulties. Metal plates and celluloid plates made so as to fit the individual case can be used with success in a certain small percentage of the cases. It is difficult to enforce their use, as they are an abomination to most patients, especially to women, and are not constantly worn. Pads which are sewed to an insole are difficult to keep applied for the reason that they pack down and slip about in the shoe. The success that usually follows the use of a circular adhesive bandage suggested to me the appliance which I will now describe.

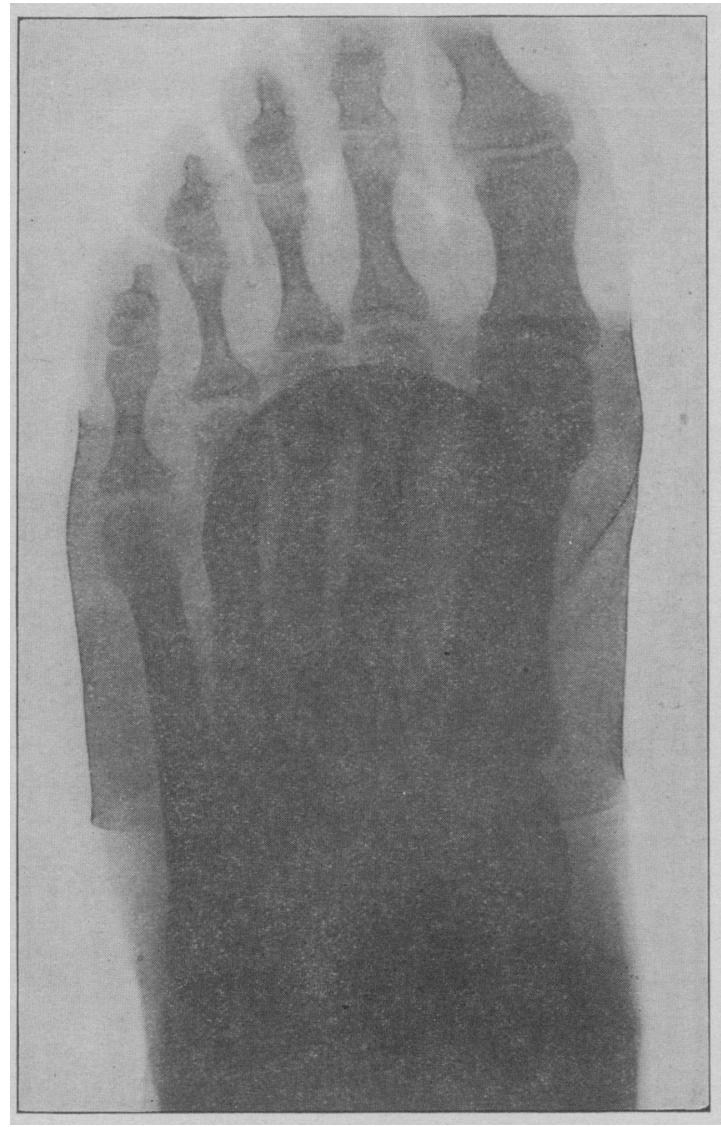

FIG. 3. Skiagram of the foot with bandage and pad in place, Fig. 3. Skiagram of the foot with bandage and pad in place, showing support directly under the second and third
sal bones, keeping them in anatomical relationship.

It is made on a cast of the foot which is taken as high on the dorsum and sides as the mediotarsal joint. Under the anterior arch of this cast a depression is cut, deep or shallow, circular or elliptical, to suit the individual case. This depression should have its greatest point of concavity behind the location of the heads of the second and third metatarsals, and should be so cut that it approximately restores the normal relationship of the metatarsal bones. Into this depression the leather worker fits either a hard

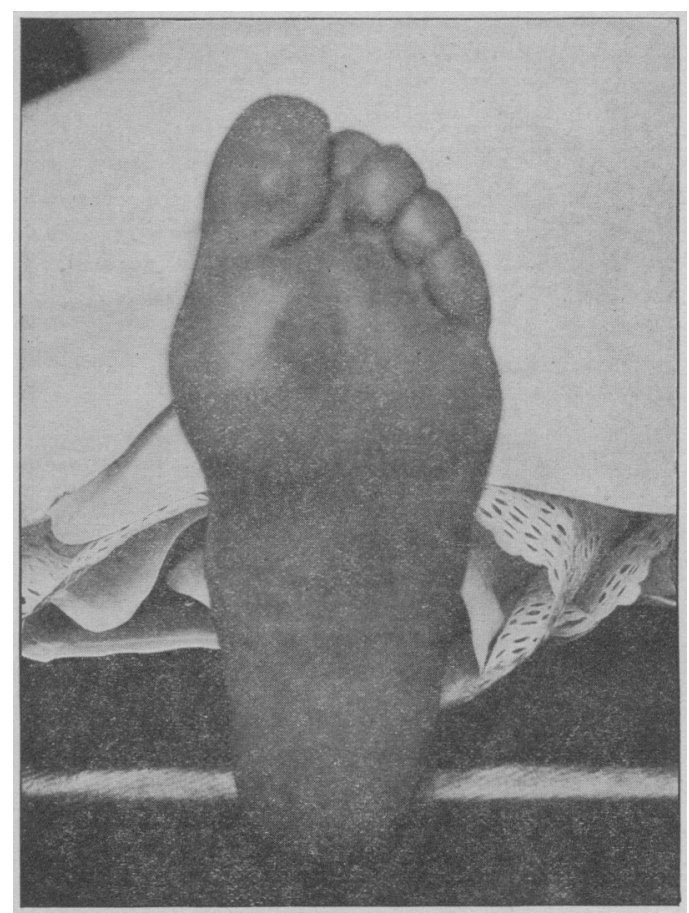

Fig. 4. Characteristic callosity under the second and third metatarsal hearls. (Hardaway and Allison, Journal of Cuta. eous Diseases, March, 1906.)

leather or a compact felt pad and this he sews to a circular leather bandage which is made of light non-stretchable leather, the dimensions of which are marked out by the surgeon on the cast of the foot. It will be found that the slight hallux valgus which exists in most cases will aid in keeping this pad and bandage from slipping backwards, as the leather is made to closely fit the shape of the foot at the head of the first metatarsal. The bandage is laced together through holes cut in the two edges over the dorsum of the foot with a light string. No eyelets should be placed in these holes and the leather of the bandage should be soft and of the variety that will not crease. (Fig. 3.)

This appliance has the following points in its favor: It is light, it is durable, it gives firm support where support is needed, and this support is held constantly in the right spot.

It has been my cxpcrience in a considerable number of cases that the appliance has worked for the relief of symptoms with much greater facility than either of the other appliances in common use, i. e., metal plates or pads sewed to an insole. (Fig. 4.)

Support having been thus accurately supplied, the question arises, Should it be continued through- 
out life or should the individual endeavor to overcome his or her muscular weakness? To this end I have found of the greatest value the exercises recommended by Osgood ${ }^{5}$ in a recent article, which encourage the development of good plantar muscles and good grasping function in the toes. Ten or fifteen minutes given a day to systematic use of the anterior part of the foot, and an attempt at education of the muscles which move the toes, will result in a great improvement in a short space of time. The gait will become elastic and comfortable. The excision of the head of the fourth metatarsal bone is rarely necessary and rarely done at the present time. There seems to be no reason for this operation. The question of proper shoes is one that requires very careful adjustment, as it is necessary to supply the patient with a shoe that has a broad enough toe for comfortable use and also one that makes some concessions to style.

REFERENCES.

1 T. G. Morton: Am. Jour. Med. Sc., 1876.

2 Joel E. Goldthwait: Boston MED. AND SuRa. Jour., vol. exxxi p. 233. Trans. Am. Orthop. Asso., vol. vii, 1894

W. A. Hardaway and Nathaniel Állison: Jour. Cutan. Dis.

March, 1906. Trans. Am. Orthop. Asso., 1906.

\section{NERVE-STRAIN OF SCHOOL CHILDREN.*}

BY LOUIS W. FLANDERS, M.D., DOVER, N. H.

IN some respects the child of to-day has come into a goodly heritage. The increased knowledge on the part of medical men, the more stringent enforcement of sanitary laws and the better education of the parents with regard to the health of the child have placed him upon a much safer platform than that occupied by the child of thirty or forty years ago. But, unfortunately, with all this improvement of the child's physical condition, there is coming to be a constantly increasing demand upon his intellectual capacity, so that we are in danger of losing all we have gained by substituting in the place of former coarser ills the more insidious derangements which result from an overtaxed nervous system.

Every day brings to the oculist its proportion of child patients. It is a daily story of eyes-ache, headache, nervousness, fretfulness, lassitude, loss of appetite and troubled sleep. To all outward appearances these children are well nourished, but a closer inspection will reveal that their muscles lack the wiry hardness of the country child of forty years ago. It is a case of development of brain at the expense of brawn. Of course not all children are of this class. Many are able to endure the excessive demands made upon them without loss of health, but the proportion of neurasthenics is constantly increasing and it is a grave question whether, if the present pace is continued, we may not have a generation of nervous invalids ahead of us. Up to the age of twelve years the boy and the girl should be treated just alike physically. They are both young ani-

2* Read before the New Hampshire State Medical Society at the annual meeting of 1907 . mals and should have a few hours of study, a few hours of play and unlimited sleep. Five hours of close work is all that should be required of a child at this age, and if he idles away his time in school, the penalty should be loss of promotion and not curtailment of hours of recreation and sleep.

But are we always fair to children? The teacher says, or the parent admits, that a child does not apply himself during school hours.

When we are about to prepare a paper for these meetings, we wait until after office hours, lock the doors, and in solemn stillness, surrounded by books and papers, the labor begins which for some of us continues many weary hours before the child is born.

Contrast your environment with the environment of the child during school hours. Surrounded by a multitude of uneasy youngsters to attract his attention, amidst a babel of noisy recitations, he is expected to solve a problem in arithmetic or to commit to memory a page of geography. I have seen conscientious children with fingers stuffed in their ears and with eyes downcast to shut out alluring visions struggling with this difficult task. Mental concentration to the exclusion of all disturbing elements is greatly to be desired and cultivated, but we should not expect it in the school child.

A year or two ago a little girl, twelve years old, an inmate of a fashionable New York boardingschool (I use the word "inmate" advisedly) was brought to me for examination. There was the usual history of nervous derangement and, inasmuch as headache and eyes-ache were especially prominent, it had been suggested that eye-strain might be the cause of the trouble. Now there was absolutely nothing wrong with that child's eyes and so I began to question her about her work. I said,

"How many studies do you have?"

"Four: Arithmetic, English, spelling and geography," or something like that.

I said, "Music, of course?" Yes, she had a music lesson once a week and practised an hour a day.

"And drawing and painting?" Yes, she had a drawing lesson once a week. "And dancing?" Yes, she had a dancing lesson once a week.

Then I turned to the mother and said, "Is this all she has in the way of studies?"

"Well," the mother replied, "she is a nice little French scholar and she has an hour a week of French conversation."

"And is that all?" I persisted.

"Yes, unless you call a lesson in elocution a study."

Then turning to the little patient, I asked her how much exercise she took. She said she spent an hour in the gymnasium every forenoon. "But don't you get any out-of-door exercise?" Oh, yes, they were obliged to go to walk with the teachers for an hour and a half every pleasant afternoon.

Can't you see that walk? That little string of galley slaves with a teacher in front and one 